\title{
Sucrose ingestion causes opioid analgesia
}

\author{
F.N. Segato ${ }^{1}$, \\ C. Castro-Souza ${ }^{1}$, \\ E.N. Segato ${ }^{1}$, \\ S. Morato ${ }^{2}$ and \\ N.C. Coimbra ${ }^{1}$
}

\author{
${ }^{1}$ Laboratório de Neuroanatomia e Neuropsicobiologia, Departamento de Morfologia, \\ Faculdade de Medicina de Ribeirão Preto, Universidade de São Paulo, \\ 14049-900 Ribeirão Preto, SP, Brasil \\ 'Laboratório de Psicobiologia, Departamento de Psicologia e Educação, \\ Faculdade de Filosofia, Ciências e Letras de Ribeirão Preto, \\ Universidade de São Paulo, 14049-901 Ribeirão Preto, SP, Brasil
}

\section{Correspondence \\ N.C. Coimbra \\ Laboratório de Neuroanatomia \\ e Neuropsicobiologia \\ Departamento de Morfologia \\ FMRP, USP \\ Av. Bandeirantes, 3900 \\ 14049-900 Ribeirão Preto, SP \\ Brasil \\ Research supported by FAEPA (No. 537/95) and FAPESP \\ (No. 95/3604-4) to N.C. Coimbra and CNPq (No. 523094/95-7) to \\ S. Morato.}

Received November 28, 1996

Accepted June 24, 1997

$\ldots \ldots \ldots \ldots \ldots \ldots \ldots \ldots$

\section{Abstract}

The intake of saccharin solutions for relatively long periods of time causes analgesia in rats, as measured in the hot-plate test, an experimental procedure involving supraspinal components. In order to investigate the effects of sweet substance intake on pain modulation using a different model, male albino Wistar rats weighing 180-200 g received either tap water or sucrose solutions $(250 \mathrm{~g} / \mathrm{l})$ for 1 day or 14 days as their only source of liquid. Each rat consumed an average of $15.6 \mathrm{~g}$ sucrose/ day. Their tail withdrawal latencies in the tail-flick test (probably a spinal reflex) were measured immediately before and after this treatment. An analgesia index was calculated from the withdrawal latencies before and after treatment. The indexes (mean $\pm \mathrm{SEM}, \mathrm{N}=12$ ) for the groups receiving tap water for 1 day or 14 days, and sucrose solution for 1 day or 14 days were $0.09 \pm 0.04,0.10 \pm 0.05,0.15 \pm 0.08$ and $0.49 \pm$ 0.07 , respectively. One-way ANOVA indicated a significant difference $\left(\mathrm{F}_{(3,47)}=9.521, \mathrm{P}<0.001\right)$ and the Tukey multiple comparison test $(\mathrm{P}<0.05)$ showed that the analgesia index of the 14-day sucrose-treated animals differed from all other groups. Naloxone-treated rats $(\mathrm{N}=7)$ receiving sucrose exhibited an analgesia index of $0.20 \pm 0.10$ while rats receiving only sucrose $(\mathrm{N}=7)$ had an index of $0.68 \pm 0.11(\mathrm{t}=0.254$, 10 degrees of freedom, $\mathrm{P}<0.03)$. This result indicates that the analgesic effect of sucrose depends on the time during which the solution is consumed and extends the analgesic effects of sweet substance intake, such as saccharin, to a model other than the hot-plate test, with similar results. Endogenous opioids may be involved in the central regulation of the sweet substance-produced analgesia.

Antinociception is properly defined as a reduction in the response of sensory systems to noxious stimuli. Pain sensation and those aspects of the behavioral responses to pain that depend upon neural processing in the brain require nociceptive signals to be transmitted through ascending pathways from the spinal cord and the trigeminal nuclei in the brain stem and thalamus (1). Hagbarth and Kerr (2) provided the first direct evidence
Key words

- Antinociception

- Sucrose intake

- Tail-flick test

- Endogenous opioids

- Rats

- Naloxone that supraspinal brain sites could control ascending sensory pathways, and Carpenter et al. (3) demonstrated descending control of sensory input to ascending pathways.

There is evidence that the consumption of sweet palatable solutions produces analgesia in animals. It has been reported that rats drinking saccharin for relatively long periods of time show an increase in the latency of paw withdrawal in the hot-plate 
test; saccharin consumption also made the rats tolerant to the effects of morphine, suggesting the involvement of opioid receptors $(4,5)$. Tolerance to morphine analgesia has been also observed in diabetes mellitus $(6,7)$ and mice with diabetes are selectively hyperresponsive to delta ${ }_{1}$ opioid receptor-mediated antinociception (8). In addition, Blass et al. (9) reported that contact with a small amount of sucrose solution on the tongue of 10-day old rat pups rapidly increased the latency of paw withdrawal in a hot-plate test.

The hot-plate test is an experimental procedure that involves supraspinal components (10). Thus, it would be interesting to investigate whether sucrose has the same analgesic effects as saccharin and whether these effects would still be present when an experimental model based on a different mechanism mediating pain is used. In the present study we investigated the tail-flick response to noxious heat, which is probably a spinal reflex $(10,11)$. The use of different models for measuring pain is important because the analgesic effects of saccharin and sucrose could be due to one or more mechanisms. For example, brief shock restricted to the front paws produced analgesia reversed by naloxone, as measured by the tail-flick test (12), whereas even high doses of naloxone failed to reduce the analgesia induced by shocks applied to the hind paws (13). This indicates that the application of shocks to the front paws activates an opiate system, since low doses of naloxone antagonize this analgesia, while shocks applied to the hind paws produce an analgesia which is not reversed even at high doses of naloxone (13). Since some neural pathways and some neurotransmitters play an important role in the complex modulation of pain transmission, the investigation of these modulatory mechanisms may have important implications for pain treatment.

Male Wistar rats from the Animal House of the Campus of the University of São Paulo at Ribeirão Preto were used. The animals, weighing 180-200 g, were housed six to a cage with free access to food and water throughout the experiment.

Each animal was placed in an acrylic tube and its tail laid across a nichrome wire coil which was then heated by the passage of an electric current. The current raised the temperature of the coil at a rate of $9^{\circ} \mathrm{C} / \mathrm{s}$. If necessary, small adjustments of the current were made at the beginning of the experiment in order to obtain three consecutive baseline tail-flick latencies (TFL) of 2.5 to $3.5 \mathrm{~s}$. If at any time the animal failed to flick its tail within $6 \mathrm{~s}$, the tail was removed from the coil to prevent damage to the skin. Three measures of TFL were taken at 5-min intervals. Each TFL measurement was normalized by an index of analgesia (IA) using the formula:

$$
\mathrm{IA}=\frac{\left(\mathrm{TFL}_{\text {test }}\right)-\left(\overline{\mathrm{TFL}}_{\mathrm{control}}\right)}{6-\left(\overline{\mathrm{TFL}}_{\mathrm{control}}\right)}
$$

The animals were manipulated and placed in the acrylic tube daily for one week in order to habituate to the researcher and to the tailflick apparatus. After three days of habituation, three TFL measures were taken for each rat. In order to assess the effects of sucrose on the tail-flick latencies, the animals were divided into four groups $(\mathrm{N}=12)$ continuously receiving either tap water or sucrose solution $(250 \mathrm{~g} / \mathrm{l})$ for $24 \mathrm{~h}$ or 14 days, after which they were submitted to three TFL measures. In two other groups of rats (N $=7$ ) tail-flick latencies were also recorded 10 min after $i p$ administration of the opioid antagonist naloxone $(1 \mathrm{mg} / \mathrm{kg})$ or saline. Each animal consumed an average of $15.62 \mathrm{~g}$ of sucrose per day and in the 24-h group ingestion included the overnight period (when rodents are more active). All tests were performed at the beginning of the dark period (starting at 17:00 h).

Tail-flick latency measurements before and after the sucrose treatment were transformed into an analgesia index. The indexes 
were analyzed by one-way analysis of variance followed, when appropriate, by the Tukey multiple comparison test. The Student $t$-test was also used for the second experiment. All tests were run using a statistical software package.

Analysis of variance indicated a significant difference $\left(\mathrm{F}_{(3,47)}=9.521, \mathrm{P}<0.001\right)$ and the Tukey multiple comparison test $(\mathrm{P}<0.05)$ revealed that the analgesia index for the 14day sucrose-treated animals differed from that for all other groups (Figure 1). This indicates that treatment with sucrose for 14 days causes analgesia, an effect that depended on the number of days of sucrose intake, since it was not observed when the rats received sucrose for just one day. The second experiment showed that peripheral administration of naloxone antagonized the analgesic effect of sucrose ingestion (Figure 2).

The present results indicate that sucrose also provokes analgesic effects when ingested for a relatively long period of time, in agreement with the finding that saccharin ingested for four weeks produces analgesia $(4,5)$. The effect observed here, however, was produced after 14 days, which is a shorter time. It also extends the results to a different experimental model, which produces pain mediated mainly at the spinal level. This suggests that the contact with sweet substances may have caused the effect, without the need for actual intake, since Blass et al. (9) have also produced analgesia in the hotplate test without actual ingestion just by placing a few drops of sucrose solution on the tongue of rat pups. It is difficult to account for these effects of sweet substances since there are no known connections between taste and pain mechanisms. The present results also indicate that opioid antagonists such as naloxone can antagonize sucrose-produced analgesia, suggesting that endogenous opioids may be involved in the modulation of this response. In fact it has been demonstrated that opioid receptors are

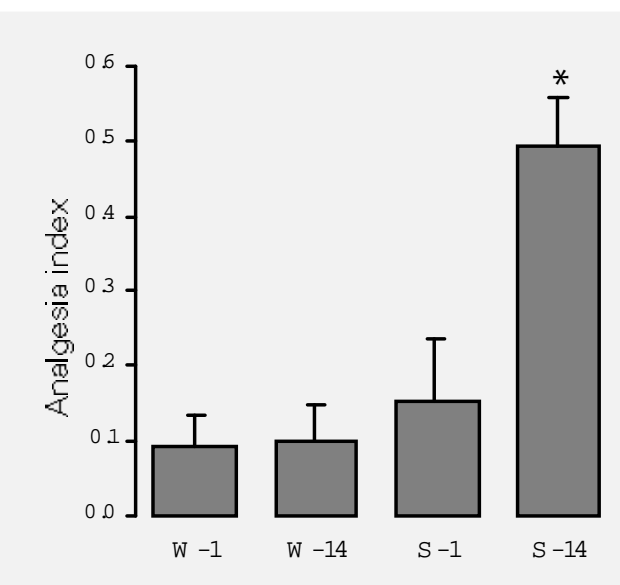

Figure 1 - Analgesia indexes of rats receiving tap water or sucrose solutions (250 g/l) for 1 or 14 days. W, Water; S, sucrose. Data are reported as mean \pm SEM for 12 rats in each group. ${ }^{*} \mathrm{P}<0.05$ compared to all other groups (Tukey test).

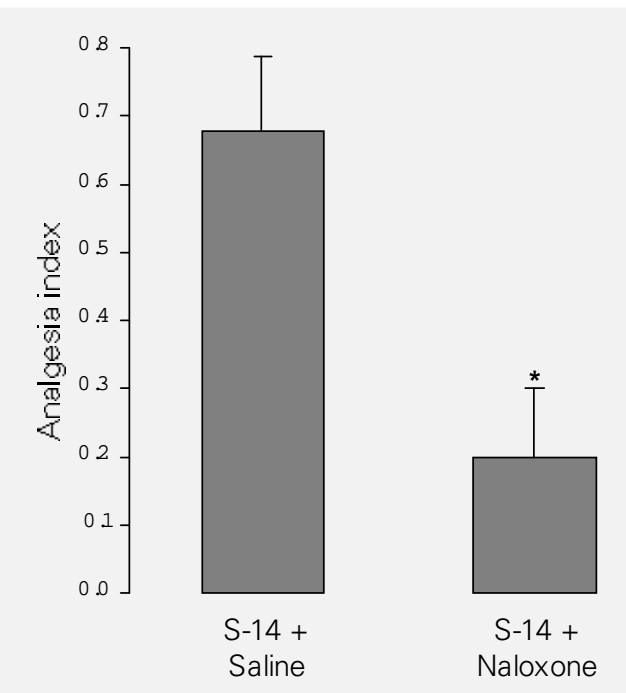

Figure 2 - Analgesia indexes of rats receiving sucrose solutions (250 g/l) for 14 days and ip injections of saline $(0.9 \% \mathrm{NaCl})$ or naloxone (1 mg/kg). Data are reported as mean \pm SEM for 7 rats in each group. ${ }^{*} \mathrm{P}<0.05$ compared to saline-treated rats (Student $t$-test).

involved in analgesia induced by ingestion of saccharin $(4,5)$. However, the effect of endogenous opioids may be also correlated with serotonin release from the spinal cord in diabetic rats (14). Recent studies have provided evidence that the pain occurring in diabetic neuropathy can be attenuated by indirect activation of central $5-\mathrm{HT}_{1}$ and 5$\mathrm{HT}_{2}$ receptors (15), and that 5-hydroxytryptaminergic antinociceptive pathways are barely affected by diabetes (16).

\section{Acknowledgment}

The authors are grateful to D.S. SouzaFilho for expert technical assistance. 


\section{References}

1. Willis WD (1989). The origin and destination of pathways involved in pain transmission. In: Wall PD \& Melzack R (Editors), Textbook of Pain. Churchill Livingstone, Edinburg, 112-127.

2. Hagbarth KE \& Kerr DIB (1954). Central influences on spinal afferent conduction. Journal of Neurophysiology, 17: 295-307.

3. Carpenter D, Engberg I \& Lundberg A (1965). Differential supraspinal control of inhibitory and excitatory actions from the FRA to ascending spinal pathways. Acta Physiologica Scandinavica, 63: 103-110.

4. Bergmann F, Cohen E \& Lieblich I (1984). Biphasic effects of chronic saccharin intake on pain responses of healthy and diabetic rats of two genetically selected strains. Psychopharmacology, 82: 248251.

5. Lieblich I, Cohen E, Ganchrow JR, Blass EM \& Bergmann F (1983). Morphine tolerance in genetically selected rats induced by chronically elevated saccharine intake. Science, 221: 871-873.

6. Kamei J, Suzuki T, Misawa M, Nagase H \& Kasuya $Y$ (1995). Antinociceptive effect of dihydroethorphine in diabetic mice. European Journal of Pharmacology, 275: 109-113.
7. Rami MA, Chandran U, Andrade C \& Venkataraman BV (1996). Felodipine potentiates morphine analgesia in control and streptozotocin diabetic female rats. Journal of Experimental Biology, 34: 663666.

8. Kamei J, Saitoh A, Ohsawa M, Suzuki T, Misawa M, Nagase H \& Kasuya Y (1995). Antinociceptive effects of the selective non-peptidic delta-opioid receptor agonist TAN-67 in diabetic mice. European Journal of Pharmacology, 276: 131-135.

9. Blass E, Fitzgerald E \& Kehoe P (1987). Interaction between sucrose, pain and isolation distress. Pharmacology, Biochemistry and Behavior, 26: 483-489.

10. Yaksh TL \& Rudy TA (1976). Analgesia mediated by a direct spinal action of narcotics. Science, 192: 1357-1358.

11. Mayer DJ \& Liebeskind JC (1974). Pain reduction by focal electrical stimulation of the brain: an anatomical and behavioural analysis. Brain Research, 68: 73-93.

12. Cobelli DA, Watkins LR \& Mayer DJ (1980). Society for Neuroscience Abstracts, 6: 247. Apud: Watkins LR \& Mayer DJ (1982). Organization of endogenous opiate and nonopiate pain control systems. Science, 216: 1185-1192.
13. Watkins LR \& Mayer DJ (1982). Organization of endogenous opiate and nonopiate pain control systems. Science, 216: 11851192.

14. Suh HW, Song DK, Wie MB, Jung JS, Hong HE, Choi SR \& Kim YH (1996). The reduction of antinociceptive effect of morphine administered intraventricularly is correlated with the decrease of serotonin release from the spinal cord in streptozotocin-induced diabetic rats. General Pharmacology, 27: 445-450

15. Takeshita N, Ohkubo $Y$ \& Yamaguchi I (1995). Tiapride attenuates pain transmission through an indirect activation of central serotonergic mechanism. Journal of Pharmacology and Experimental Therapeutics, 275: 23-30.

16. Takeshita N \& Yamaguchi I (1995). Metachlorophenylpiperazine attenuates formalin-induced nociceptive responses through 5-HT1/2 receptors in both normal and diabetic mice. British Journal of Pharmacology, 116: 3133-3138. 